\title{
THE UNIVALENCE OF AN INTEGRAL
}

\section{W. M. CAUSEY}

ABSTRACT. Let $f(z)$ be a normalized function, analytic and univalent in the open unit disc. It is shown that if $g(z)=\int_{0}^{z}(f(t) / t)^{\alpha} d t$, then $g$ is univalent in the open unit disc if $\alpha$ is a complex number satisfying $0 \leqq|\alpha| \leqq(\sqrt{ } 2-1) / 4$.

1. Introduction. Let $S$ be the class of functions $f(z)=z+a_{2} z^{2}$ $+\cdots$ analytic and univalent in the open unit disc $E$. Define

$$
g(z)=\int_{0}^{z}\left(\frac{f(t)}{t}\right)^{\alpha} d t .
$$

The author proved in [1] that if $f \in S$, then $g \in S$ if $\alpha$ is a complex number satisfying $0 \leqq|\alpha| \leqq(\sqrt{ } 5-2) / 4$. This bound has been improved by $M$. Nunokawa [5] to $0 \leqq|\alpha| \leqq \alpha_{0}$, where

$$
\frac{(18425)^{1 / 2}-75}{800}<\alpha_{0}<\frac{(24841)^{1 / 2}-125}{384} .
$$

These results were obtained by a method of P. L. Duren, H. S. Shapiro, and A. L. Shields [2] that utilizes a remarkable univalence criterion of $Z$. Nehari involving the Schwarzian derivative. The purpose of this paper is to improve the value of $\alpha_{0}$ to $(\sqrt{ } 2-1) / 4$.

2. We will require some lemmas. The first is Nehari's result and may be found in [3]. Lemma 2 is due to the author [1, p. 209].

LEMMA 1. Suppose that $w=f(z)$ is analytic in $E$ and $|\{w, z\}|$ $\leqq 2 /\left(1-r^{2}\right)^{2}$ for all $z \in E,|z|=r$, where $\{w, z\}=\left(w^{\prime \prime} / w^{\prime}\right)^{\prime}-\frac{1}{2}\left(w^{\prime \prime} / w^{\prime}\right)^{2}$ is the Schwarzian derivative. Then $f(z)$ is univalent in $E$.

Lemma 2. Suppose $f \in S$ and $g(z)=\int_{0}^{z}(f(t) / t)^{\alpha} d t$, then

$$
\left|g^{\prime \prime}(z) / g^{\prime}(z)\right| \leqq 2|\alpha| / r(1-r)
$$

for $0<r=|z|<1$, and

$$
\left|g^{\prime \prime}(z) / g^{\prime}(z)\right| \leqq 8|\alpha| /\left(1-r^{2}\right)
$$

for $0 \leqq r<1$.

Received by the editors March 7, 1970.

AMS 1969 subject classifications. Primary 3042.

Key words and phrases. Schwarzian derivative, Poisson integral, univalent functions. 
LEMma 3. Suppose $h(z)$ is analytic in $E$ and $|h(z)| \leqq 1 / r(1-r)$, $0<r=|z|<1$. Then

$$
\left|h^{\prime}(z)\right| \leqq 27 / 2\left\{1-9 r^{2}+\left(1+3 r^{2}\right)^{3 / 2}\right\} \equiv B(r),
$$

for $0 \leqq r<1$.

Proof. By the Cauchy integral formula

$$
h^{\prime}(z)=\frac{1}{2 \pi i} \int_{C} \frac{h(t)}{(t-z)^{2}} d t,
$$

where $C$ is the circle $|t|=R,|z|=r<R<1$. Then, if $t=R e^{i \phi}$,

$$
\left|h^{\prime}(z)\right| \leqq \frac{1}{2 \pi(1-R)} \int_{0}^{2 \pi} \frac{d \phi}{\left|z-R e^{i \phi}\right|^{2}}=\frac{1}{(1-R)\left(R^{2}-r^{2}\right)},
$$

for the integral in (4) is a Poisson integral. But this expression takes its minimum in $(r, 1)$ at $R=\frac{1}{3}+\frac{1}{3} \sqrt{ }\left(1+3 r^{2}\right)$. Substitution gives the result.

Theorem. Suppose $f \in S$ and $g(z)=\int_{0}^{z}(f(t) / t)^{\alpha} d t$. Then $g \in S$ for $0 \leqq|\alpha| \leqq(\sqrt{ } 2-1) / 4$.

Proof. From (1) and Lemma 3 it follows that

$$
\left|\left(g^{\prime \prime}(z) / g^{\prime}(z)\right)^{\prime}\right| \leqq 2|\alpha| B(r) .
$$

From Lemma 1, (2), and (5) we have

$$
\begin{aligned}
|\{g, z\}| & \leqq \frac{1}{2}\left|\left(g^{\prime \prime} / g^{\prime}\right)\right|^{2}+\left|\left(g^{\prime \prime} / g^{\prime}\right)^{\prime}\right| \\
& \leqq \frac{32|\alpha|^{2}}{\left(1-r^{2}\right)^{2}}+2|\alpha| B(r) \\
& =\frac{2}{\left(1-r^{2}\right)^{2}}\left\{16|\alpha|^{2}+\left(1-r^{2}\right)^{2}|\alpha| B(r)\right\} .
\end{aligned}
$$

Define $M(r)=\left(1-r^{2}\right)^{2} B(r)$. A calculation shows that $(d / d r) M(\sqrt{ } r)$ $>0, r \in[0,1)$, and so

$$
M(r)<\lim _{r \rightarrow 1} M(r)=8, \quad 0 \leqq r<1 .
$$

Hence $|\{g, z\}| \leqq 2 /\left(1-r^{2}\right)^{2}$ if

$$
16|\alpha|^{2}+8|\alpha|-1 \leqq 0,
$$

which is true if $0 \leqq|\alpha| \leqq(\sqrt{ } 2-1) / 4$, and the theorem follows from Lemma 1.

The author wishes to thank the referee for helpful suggestions. 


\section{REFERENCES}

1. W. M. Causey, The close-to-convexity and univalence of an integral, Math. Z. 99 (1967), 207-212. MR 35 \#6807.

2. P. L. Duren, H. S. Shapiro and A. L. Shields, Singular measures and domains not of the Smirnov type, Duke Math. J. 33 (1966), 247-254. MR 33 \#7506.

3. Z. Nehari, The Schwarzian derivative and schlicht functions, Bull. Amer. Math. Soc. 55 (1949), 545-551. MR 10, 696.

4. M. Nunokawa, On the univalency and multivalency of certain analytic functions, Math. Z. 104 (1968), 394-404. MR 37 \#2971.

5. - On the univalence of a certain integral, Trans. Amer. Math. Soc. 146 (1969), 439-446. MR 40 \#4436.

6. W. C. Royster, On the univalence of a certain integral, Michigan Math. J. 12 (1965), 385-387. MR 32 \#1342.

University of Mississippi, University, MississipPi 38677 